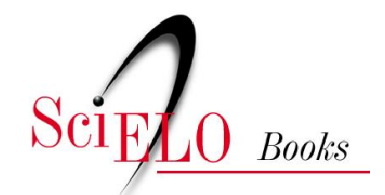

\title{
Modelos de indicadores de sustentabilidade para gestão de recursos hídricos
}

\author{
Cícero de Sousa Lacerda \\ Gesinaldo Ataíde Cândido
}

\section{SciELO Books / SciELO Livros / SciELO Libros}

LACERDA, CS., and CÂNDIDO, GA. Modelos de indicadores de sustentabilidade para gestão de recursos hídricos. In: LIRA, WS., and CÂNDIDO, GA., orgs. Gestão sustentável dos recursos naturais: uma abordagem participativa [online]. Campina Grande: EDUEPB, 2013, pp. 13-30. ISBN 9788578792824. Available from SciELO Books $<$ http://books.scielo.org $>$

\section{(c) $\frac{1}{\mathrm{BV}}(2)$ (2)}

All the contents of this work, except where otherwise noted, is licensed under a Creative Commons Attribution-Non Commercial-ShareAlike 3.0 Unported.

Todo o conteúdo deste trabalho, exceto quando houver ressalva, é publicado sob a licença Creative Commons Atribuição Uso Não Comercial - Partilha nos Mesmos Termos 3.0 Não adaptada.

Todo el contenido de esta obra, excepto donde se indique lo contrario, está bajo licencia de la licencia Creative Commons Reconocimento-NoComercial-CompartirIgual 3.0 Unported. 


\title{
Modelos de indicadores de sustentabilidade para gestão de recursos hídricos
}

\author{
Cícero de Sousa Lacerda \\ Gesinaldo Ataíde Cândido
}

\section{Introdução}

O contexto atual solicita cada vez mais do universo acadêmico, posicionamentos mais concisos frente às dificuldades emergentes e em especial no contexto das dinâmicas que configuram a utilização dos recursos naturais. Pois o modelo de desenvolvimento econômico posto desde a revolução industrial tem causado vários danos ao meio ambiente. Portanto recursos naturais eram utilizados de forma desordenada e predatória sem pensar nos limites de carga.

Nessa perspectiva, a partir dos anos 70, a sociedade começa a desperta o interesse pelas questões que envolvia os métodos de produção para o desenvolvimento e os recursos naturais. Nesse período, surge o conceito de sustentabilidade associado ao estabelecimento de limites ao crescimento, no início dos anos 70 do século XX. Diante da possibilidade de escassez de recursos naturais e da redução gradativa da qualidade de vida, a perspectiva da sustentabilidade tem se fortalecido e novos modelos de desenvolvimento têm sido propostos, com o objetivo de garantir a manutenção da qualidade ambiental para que as futuras gerações possam continuar a usufruir dos recursos naturais disponíveis hoje.

Em 1987, a partir do Relatório Brundtland "Our Common Future" (1991) elaborado a pedido da Assembleia Geraldas Nações Unidas, define o conceito de Desenvolvimento Sustentável como o desenvolvimento 
que satisfaz as necessidades atuais sem comprometer a capacidade das gerações futuras de satisfazerem as suas próprias necessidades. O desenvolvimento desse conceito levou a que se considerasse a sustentabilidade como um meio para alcançar um desenvolvimento humano estável. As linhas estratégicas para alcançar este objetivo são a obtenção de maiores níveis de sustentabilidade nos planos social, ambiental e econômico. Os critérios para alcançar esses níveis devem incluir medidas de mudança que sejam percebidas como socialmente aceitáveis e desejáveis ambientalmente viáveis e economicamente realizáveis.

O conceito de desenvolvimento sustentável se disseminou por diversos setores da economia, e a consciência da sociedade sobre a importância da preservação ambiental para a manutenção da qualidade de vida é cada vez maior. Nesse sentido, a questão ambiental passou a receber uma maior atenção por parte da sociedade, que começou a sentir as consequências dos impactos das atividades antrópicas sobre o meio ambiente e, diante disso, tem aceitado com mais facilidade a necessidade de mudança no atual modelo de desenvolvimento.

Para tanto se faz necessário que diante de tantas discussões a respeito da sustentabilidade e do desenvolvimento sustentável, que seus conceitos sejam compreendidos e incorporados por todos os indivíduos e instituições. E que esses conceitos saiam das discussões para a praticidade do dia a dia de cada um. Nesse sentido, o desenvolvimento sustentável passa a ser o processo de mudança social e elevação das oportunidades da sociedade compatibilizando no tempo e no espaço, o crescimento e a eficiência econômica, a conservação ambiental, a qualidade vida e a equidade social partindo de claro compromisso com o futuro e a solidariedade com as futuras gerações.

Sendo assim, o desenvolvimento sustentável como alternativa de conservação e continuidade dos recursos, interagindo com diferentes áreas econômicas, precisa de ferramentas que possam mensurar a sustentabilidade de suas ações. Para Candido e Martins (2010), a mensuração do desenvolvimento sustentável é fornecer elementos concretos que possam auxiliar nas tomadas de decisões sendo um poderoso recurso de apoio ao planejamento das ações futuras. Nessa perspectiva, surgem nos anos 90 os indicadores de sustentabilidade com objetivo de verificar o grau de realização dos objetivos propostos pelo desenvolvimento sustentável. Diversos indicadores foram desenvolvidos visando a fornecer subsídios para a tomada de decisão de governos, empresas e a sociedade em geral. Tais indicadores podem ser de âmbito global, regional ou específico. 
Reforçando essa discussão, o capítulo 40 da Agenda 21 aborda sobre as tomadas de decisões que "é necessário elaborar indicadores de desenvolvimento sustentável, a fim de que eles constituam uma base útil à tomada de decisão a todos os níveis”. Para tanto, os indicadores passam a ser uma importante ferramenta para o desenvolvimento sustentável.

Neste contexto, os indicadores de sustentabilidade, à luz de Martins e Cândido (2008), "são essenciais para concretizar um processo de desenvolvimento em bases sustentáveis”. Por sua vez, em função do alto nível de dependência que os seres humanos e demais seres vivos possuem com relação ao uso da água, agravantes implicações podem decorrer em função da sua pouca disponibilidade tanto em qualidade como em quantidade.

Afirma Barbosa (2008): "A água potável é um recurso natural finito e sua quantidade usável, per capita, diminui a cada dia com o crescimento da população mundial e com a degradação dos mananciais". Portanto, é necessário desenvolver ferramentas de avaliação e controle que orientem a gestão no sentido de diminuir os impactos relacionados aos recursos hídricos. Segundo a ONU, o consumo da água dobrou em relação ao crescimento populacional no último século. Nos dias atuais, em função dos consideráveis progressos sociais e industriais obtidos pela humanidade, pode-se enumerar, entre outros, os seguintes usos múltiplos: abastecimento urbano, irrigação, piscicultura, geração de energia elétrica, controle de cheias, regularização de vazão, diluição de esgotos e preservação da flora e fauna. Devido ao aumento e diversificação dos usos dos recursos hídricos, ao crescimento populacional e a escassez, conflitos e problemas frequentes começaram a aparecer em muitas regiões do mundo.

Os recursos hídricos além de atender os diferentes interesses humanos antes eram considerados um bem, infinitos como afirma Grecco, (1998), a água atende aos múltiplos interesses humanos e ocupa 75\% da superfície de nosso planeta. Do volume total, $97 \%$ estão nos oceanos e mares e são salgadas, e outros $2 \%$ estão armazenados nas geleiras, em lugares quase inacessíveis. Apenas $1 \%$ de toda água do planeta está disponível para o uso e desta, menos de 0,02\% é água doce superficial.

Durante muito tempo, a água foi considerada um recurso infinito. Apesar de se acreditar que a natureza fazia crer em inesgotáveis mananciais, abundantes e renováveis. No entanto, o mau uso, aliado à crescente demanda, vem preocupando os responsáveis pela gestão dos recursos 
hídricos, em função da diminuição da disponibilidade de água limpa em todo o planeta. Segundo a World Health Organization (2001), temos um quadro assustador de deficiências: 15 milhões de crianças morrem todo ano por falta de água potável; $80 \%$ das doenças e 30\% dos óbitos que ocorrem no mundo estão relacionados a água contaminada. Ressalta a Organização das Nações Unidas (2006), 50\% da taxa de doenças e morte nos países em desenvolvimento ocorrem por falta de água ou pela sua contaminação. Nestes países, para cada 1.000 litros de água utilizados, outros 10 mil são poluídos, 1,1 bilhão de pessoas em todo o mundo não têm acesso a água potável, e esta situação ainda tende a se agravar como mostram os dados do International Water Management Institute (2006), que projeta para o ano de 2025 um total de 1,8 bilhão de pessoas de diversos países vivendo em absoluta falta de água, o que equivale a mais de $30 \%$ da população mundial. Para reverter esta situação preocupante, tem sido criados métodos de tratamento de água, legislação específica, comitês de bacias hidrográficas, entre outras medidas. No entanto, o processo de mudança do uso da água desencadeado por essas iniciativas é extremamente lento e gradual. Portanto, é necessário criar instrumentos de gestão e politicas que venham preservar os recurso hídricos de forma mais efetiva e com maior agilidade, no sentido de prevenir um colapso maior quanto a falta da água em um futuro mais próximo.

Nesse sentido, a gestão de recursos hídricos com vista a sustentabilidade busca implementar um conjunto de ações destinadas a regular o uso, o controle e a proteção dos recursos hídricos, em conformidade com a legislação e normas pertinentes. Também se faz necessário integrar projetos e atividades com o objetivo de promover a recuperação e a preservação da qualidade e quantidade dos recursos das bacias hidrográficas como também a recuperação e preservação de nascentes, mananciais e cursos d'água em áreas urbanas. E para um melhor monitoramento dessa gestão visando à sustentabilidade dos recursos hídricos, será importante a utilização de indicadores de sustentabilidade. Para tanto, os indicadores de sustentabilidade hídrica surgem como ferramentas que ajudam refletir e comunicar uma ideia complexa. São úteis para observar, descrever e avaliar estados atuais, formular estados desejados ou comparar um estado atual com um desejado para o futuro. Diante o exposto, como os indicadores de sustentabilidade podem viabilizar a gestão dos recursos hídricos na perspectiva do desenvolvimento sustentável? 
A partir destas considerações, o objetivo dessa pesquisa é analisar os modelos de indicadores de sustentabilidade que são utilizados na gestão dos recursos hídricos. Para elaboração desse trabalho, foi utilizado o método de pesquisa bibliográfica documental através de artigos científicos, dissertações e teses, sobre os diferentes modelos de indicadores de sustentabilidade utilizados para gestão dos recursos hídricos. Para Vergara (1988), a pesquisa bibliográfica, possibilita a ampliação do conhecimento sobre diferentes fatos através de dados secundários.

Partindo dessa linha de raciocínio, o trabalho encontra-se estruturado em uma introdução, que traz uma abordagem sobre a temática sustentabilidade, gestão dos recursos hídricos e indicadores de sustentabilidade. $\mathrm{Na}$ fundamentação teórica, apresentamos os conceitos e reflexões sobre o desenvolvimento sustentável e os modelos de indicadores de sustentabilidade utilizados na gestão dos recursos hídricos. Em seguida, as considerações finais trazem uma reflexão sobre a análise dos modelos de indicadores de sustentabilidade que são utilizados na gestão dos recursos hídricos com os seus benefícios e limitações.

\section{Desenvolvimento Sustentável}

$\mathrm{Na}$ atualidade, é fácil perceber quadros de desequilíbrios com consequências negativas para a composição dos ecossistemas e com reflexos diretos nos ambientes sociais. De uma maneira em geral, o reflexo mais evidente tem sido o da insustentabilidade, requerendo posicionamentos do campo científico, político e do processo gestionário. Dentre os problemas sociais, o que mais tem se destacado é a pobreza em centros urbanos e nas áreas rurais como também o uso desenfreado dos recursos naturais e exclusão dos atores sociais e institucionais nas tomadas de decisões e na participação da elaboração das estratégias de desenvolvimento.

Dessa forma, o conceito de desenvolvimento sustentável, elaborado a partir do Relatório Nosso Futuro Comum, busca por limites ao sistema de desenvolvimento econômico visando a atender as necessidades presentes da humanidade, preservar e conservar os recursos existentes no sentido de garantir o sustento das gerações futuras e a manutenção dos ecossistemas. Segundo Lemos apud Nunes (2001), o conceito de desenvolvimento sustentável é fácil perceber, pois é um puro senso, mas é extremamente complexo quando se tenta aplicá-lo no dia a dia. A dificuldade de se incorporar o conceito do desenvolvimento sustentável, na 
prática, parte ainda dos princípios de que a sociedade ainda se encontra presa aos paradigmas dos modelos de desenvolvimento enraizado nas práticas do capitalista de aguçar a produção e o consumo visando ao lucro.

À luz de Barreto (2004), a ideia da sustentabilidade almeja algo capaz de ser duradouro, suportável e conservável com um intuito de continuidade. Isso demonstra que a sustentabilidade prever a continuidade dos recursos e seu uso de modo suportável respeitando, assim, a capacidade e o limite de carga do ambiente. Isso demonstra a necessidade que o modelo de desenvolvimento tem de rever, mudar e orientar seus métodos de produção antes predatórios achando que os recursos naturais eram infinitos, para um modelo que possa ser cauteloso no uso e manuseio com o ambiente.

Para Martins e Candido (2010), "a sustentabilidade significa a possibilidade de se obterem continuamente condições iguais ou superiores de vida em um dado ecossistema vislumbrando o sustentáculo da vida”. Nesse sentido, a sustentabilidade busca atender às necessidade humanas presentes, a manutenção da vida sem degradar as fontes de recursos ambientais, respeitando a capacidade de suporte dos ecossistemas para que gerações futuras possam ter as suas necessidades de manutenção da vida e o ambiente possa permanecer no seu sistema cíclico dando continuidade à perpetuação da biodiversidade de forma duradoura.

Partindo dessa lógica, a consolidação do desenvolvimento sustentável, na prática, é um grande desafio e exige da sociedade uma visão holística, sistêmica e interdisciplinar invocando a proteção racional do meio ambiente natural e construído como também respeitar e integrar as comunidades locais com seus saberes na elaboração das estratégias e planejamento com vista no desenvolvimento local. Segundo Rattner (1991), o desenvolvimento sustentável precisa ser incorporado de forma pragmática, para tanto é preciso propor o uso de tecnologias apropriadas, ter educação ambiental e conscientização permanente como também promover um modelo de produção adequado e justo que vise ao manuseio de forma respeitável aos recursos naturais.

Dentre os recursos naturais, a água é um recurso finito essencial para manutenção da vida e utilizado de diferentes formas pelos modelos de desenvolvimento. Segundo Barbosa (2008), no desenvolvimento de qualquer sociedade, os recursos hídricos desempenham um papel fundamental, não só do ponto de vista econômico, mas também ambiental. 
É dentro deste contexto de desenvolvimento socioeconômico-ambiental, que o planejamento e a gestão integrada de recursos hídricos devem ser discutidos e analisados. Planejar o uso dos recursos hídricos com vista à sustentabilidade envolve uma série de componentes, limitações e atividades, que buscam a melhoria da qualidade de vida e dos ecossistemas nos contextos das bacias hidrográficas.

Segundo Corrêa et.al. (2008), a Política Nacional instituiu a bacia hidrográfica como unidade territorial de planejamento e dentre seus objetivos destacam-se: a manutenção da quantidade e da qualidade dos diversos usos ao longo do tempo, o uso racional e integrado dos recursos hídricos visando à sustentabilidade e à prevenção de eventos hidrológicos críticos tanto de origem natural quanto devido a interferências antrópicas.

Segundo Nunes (2001), a gestão dos recursos hídricos e bacias hidrográficas é um processo contínuo de análise, tomada de decisão, organização e controle das atividades desempenhadas na bacia hidrográfica, seguindo de uma avaliação dos resultados, visando à melhoria na formulação e implementação de políticas e suas consequências no futuro. Sob essa ótica, a gestão dos recursos hídricos com vista no desenvolvimento sustentável precisa de um monitoramento contínuo que será necessário ser realizado através de indicadores de sustentabilidade.

Para Martins e Candido (2010), o desenvolvimento sustentável precisa ser concebido a partir do caráter sistêmico do ambiente onde os atores estão inseridos, sendo premente a necessidade da mensuração da sustentabilidade que possibilite operacionalizar o conceito de desenvolvimento sustentável. Nesse sentido, a criação de indicadores de sustentabilidade serão os elementos de operacionalização dessa mensuração.

\section{Modelos de indicadores de sustentabilidade usados na gestão dos recursos hídricos}

Os indicadores de sustentabilidade, criados a partir dos anos 90 , buscam mensurar as ações relacionadas ao desenvolvimento sustentável e constituem uma base útil à tomada de decisão em todos os níveis. Para Martins e Candido (2008), os indicadores constituem importantes parâmetros para orientar a gestão e o planejamento de políticas e ações que podem ser desenvolvidas. 
Sendo assim, os indicadores de sustentabilidade podem contribuir muito no sentido de minimizar impasse futuros do desenvolvimento sustentável, quantificando e informando. Para Van Bellen (2006) "o objetivo principal dos indicadores é o de agregar e quantificar informações de uma maneira que sua significância fique mais aparente" e ainda ressalta que os indicadores sintetizam as informações complexas sobre um fenômeno melhorando sua informação. Partindo desse pressuposto, os indicadores servem para auxiliar nas simplificações das informações como também auxilia nas tomadas de decisões frente ao desenvolvimento sustentável.

Portanto, como a proposta do desenvolvimento sustentável é considerar os aspectos sociais, ambientais, econômicos, culturais e éticos na perspectiva de encontrar o equilíbrio, os indicares de sustentabilidades auxiliam na mensuração e avaliação das ações. Segundo Vasconcelos (2010), “os indicadores de sustentabilidade se mostram como uma importante ferramenta de mensuração uma vez que pode alertar sobre os problemas existentes". Nesse sentido, surgem os indicadores de sustentabilidade para gestão dos recursos hídricos na perspectiva de mensurar e avaliar os possíveis problemas e auxiliar nas tomadas de decisões.

O uso de ferramentas para o monitoramento da gestão de recursos hídricos justifica-se pela importância da água tanto para a sobrevivência dos seres humanos quanto para o equilíbrio do meio ambiente como um todo. Para analisar a sustentabilidade dos recursos hídricos, tem-se aplicado vários modelos de indicadores de sustentabilidade como: Indicadores de Sustentabilidade para Gestão de Recursos Hídricos no Âmbito da Bacia Hidrográfica do TietêJacaré-SP; A Exploração de um Sistema de Reservatórios: uma Análise Otimizada dos usos e Objetivos Múltiplos na Bacia do Rio Capibaribe-PE; Um Método de Modelagem de um Sistema de Indicadores de Sustentabilidade para Gestão dos Recursos Hídricos - MISGERH: o caso da bacia dos Sinos; Uso de Indicador no Diagnóstico da Efetividade no Tratamento de Água em uma Estação Pública de Abastecimento; Índice de Sustentabilidade Ambiental do Uso da Água (ISA_ÁGUA): Municípios da região do entorno do Rio Poxim, SE; Avaliação da Sustentabilidade Hídrica de Municípios Abastecidos por Pequenas Bacias Hidrográficas: O Caso de Angra dos Reis, RJ; Proposta Metodológica para o Desenvolvimento de um Índice de Sustentabilidade Hidroambiental de Áreas Serranas no 
Semiárido Brasileiro - Estudo de Caso: Maciço de Baturité, Ceará; Desenvolvimento de Indicadores de Sustentabilidade para Gestão de Recursos Hídricos no Âmbito de Comitê de Bacia Hidrográfica.

Estes modelos de indicadores buscam mensurar a sustentabilidade na gestão dos recursos hídricos em bacias hidrográficas e diferentes localidades, porém como os recursos hídricos são um bem finito que atende a diferentes interesses humanos que urge por um controle maior na sua utilização, é necessário avaliar os critérios de seleção dos indicadores, parâmetros de análises, os critérios de análises e participação da população local na gestão dos recursos hídricos no sentido de minimizar os efeitos negativos. Com base nessa discussão, é pertinente apresentar, a seguir, uma análise sobre alguns estudos de casos que utilizam alguns modelos de indicadores de sustentabilidade para recursos hídricos.

\section{Indicadores de Sustentabilidade para Gestão de Recursos Hídricos no Âmbito da Bacia Hidrográfica do Tietê-Jacaré-SP}

O presente artigo apresenta um modelo de Indicadores de Sustentabilidade, como uma ferramenta para subsidiar a gestão de recursos hídricos, no âmbito de um Comitê de Bacia Hidrográfica. A seleção dos indicadores foi realizada a partir de revisão bibliográfica e consultas à população local e especialistas. Para tanto, foram selecionados 73 indicadores. $\mathrm{O}$ modelo de indicadores foi chamando de CISGRH que devem ser monitorados, dada sua importância para conhecimento da situação dos recursos hídricos na bacia em estudo e avaliação do gerenciamento no sentido de poder melhor subsidiar as políticas públicas para minimização dos impactos e do mau uso dos recursos hídricos. Ao longo do tempo, o monitoramento destes indicadores poderá corroborar no traçado da evolução das condições dos recursos hídricos na região e avaliação em relação às ações previstas e empreendidas pelo comitê de bacia. Este modelo traz boas contribuições para o gerenciamento dos recursos hídricos, pois o mesmo estabelece critérios de seleção dos indicadores, parâmetros de análises e participação da população local na seleção dos indicadores, porém a sua forma de aplicabilidade não ficou bem clara no sentido de facilitar a reaplicação em outras áreas. 


\section{A Exploração de um Sistema de Reservatórios: uma Análise Otimizada dos usos e Objetivos Múltiplos na Bacia do Rio Capibaribe-PE}

Este trabalho se constitui em uma aplicação de uma abordagem que combina as técnicas de otimização e simulação, o planejamento e operação do uso da água para um sistema integrado de recursos hídricos formado por cinco reservatórios, para atendimento das demandas de abastecimento humano, vazão ecológica, irrigação, piscicultura e controle de cheias, alguns destes usos conflitantes. Para tanto, foram incorporados neste estudo os cálculos dos indicadores de sustentabilidade dos reservatórios, confiabilidade, resiliência e vulnerabilidade, permitindo avaliar a disponibilidade hídrica e o desempenho do sistema para cada um dos cenários. Além desses indicadores, foram calculados indicadores que avaliaram o desempenho das áreas irrigadas. Nesse sentido, foram elaborados cinco indicadores para medir a eficiência dos reservatórios. $\mathrm{O}$ uso dos modelos e a análise do conjunto dos indicadores possibilitam a adoção de políticas com maior segurança para o gerenciamento da operação dos reservatórios com problemas de déficit hídrico e conflitos de uso da água. Este modelo aborda boas contribuições para a gestão dos recursos hídricos, descreve os indicadores e apresenta as formas de análises, porém não deixa claros os critérios de seleção dos indicadores e os parâmetros de análises. E como a gestão dos recursos hídricos envolve todos que estão inseridos no contexto, é de suma importância a participação da população local, que não está contemplada na seleção dos indicadores desse modelo.

\section{Um Método de Modelagem de um Sistema de Indicadores de Sustentabilidade para Gestão dos Recursos Hídricos- MISGERH: o caso da bacia dos Sinos}

Esta pesquisa desenvolveu um método de modelagem de um sistema de indicadores para avaliar a sustentabilidade do sistema dos recursos hídricos, propiciando a participação dos atores sociais, visando a ter maior conhecimento do problema e legitimidade do processo da gestão dos recursos hídricos numa bacia hidrográfica. Sendo assim, foram abordados três temas: gestão ambiental, sistemas de apoio à decisão e indicadores de sustentabilidade. Esta pesquisa foi aplicada na bacia hidrográfica do Rio dos Sinos. O sistema de indicadores é composto 
por 238 indicadores partilhados entre os Clusters locais, mostrando a interação dos indicadores e dependência entre os Clusters setoriais do sistema de recursos hídricos. Este modelo é um dos mais complexos que pode contribuir para gestão dos recursos hídricos, pois seus critérios de seleção, parâmetros e análises são bem definidos, como também contempla a participação dos atores socais locais.

\section{Uso de Indicador no Diagnóstico da Efetividade no Tratamento de Água em uma Estação Pública de Abastecimento}

Esta análise consiste na aplicação da metodologia do Indicador da Efetividade de Tratamentos de Água (IETA) para avaliar o desempenho no uso da água de uma Estação de Tratamento de Água (ETA). Assim, a partir da sistematização de informações referentes a mensurações de qualidade, quantidades e regularidades na qualidade e quantidade de água, podemos apontar o desempenho de uma Estação de Tratamento de Âgua (ETA) na recomposição do potencial ambiental da água processada. Os resultados obtidos com a pesquisa apontam para a necessidade de se melhorar a efetividade da ETA, indicando também que o IETA poderia ser utilizado no processo de gerenciamento e tomada de decisão em sistemas de abastecimento público de água. Esta metodologia contribui para gerenciamento da quantidade e qualidade da água dos reservatórios, como também contempla a participação dos atores sociais locais para seleção dos indicadores e estabelece parâmetros de análises, porém não ficaram explícitos os critérios de seleção dos indicadores como também a forma de aplicabilidade.

\section{Índice de Sustentabilidade Ambiental do Uso da Água (ISA_ÁGUA): Municípios da região do entorno do Rio Poxim - SE}

Este estudo foi realizado em seis municípios localizados no entorno da sub-bacia do Rio Poxim: Aracaju, Areia Branca, Itaporanga d'Ajuda, Laranjeiras, Nossa Senhora do Socorro e São Cristóvão com objetivos de implementar um processo de gestão dos recursos hídricos para os municípios do entorno da região do Rio Poxim, já que se diferencia dos demais métodos pela análise integrada do Perfil Social, Econômico 
e Ecológico de uma região. Este modelo é composto por 35 indicadores distribuídos pelas dimensões ecológica, econômica e social. Consideraram-se as características demográficas da população residente, dos domicílios, das atividades econômicas predominantes, juntamente com importantes aspectos ecológicos, permitindo uma avaliação do seu estado de conservação. Este modelo contribui para gestão dos recursos hídricos, principalmente no sentido de considerar as características da comunidade local, porém não ficam explícitos os parâmetros de análises dos indicadores.

\section{Avaliação da Sustentabilidade Hídrica de Municípios Abastecidos por Pequenas Bacias Hidrográficas: 0 Caso de Angra dos Reis, RJ;}

Esta pesquisa tem como objetivo apresentar uma metodologia para avaliar a sustentabilidade hídrica de municípios abastecidos por PBH em Angra dos Reis. A sustentabilidade hídrica é avaliada através de quatro indicadores: (1) quantidade hídrica, calculada através de regionalização hidrológica; (2) demanda hídrica, estimada por dados demográficos e socioeconômicos; (3) capacidade de depuração dos corpos d'água, estabelecida pelo nível de eficiência de tratamento do esgoto na eliminação da $\mathrm{DBO}$, e pelos limites de classes de uso do CONAMA; e (4) capacidade de ocupação das áreas urbanizáveis, definida por taxas de densidade demográfica e pelo Plano Diretor municipal. O resultado permite a modelagem de cenários de uso das águas e do solo, facilitando os processos de tomada de decisão, como outorga pelo uso da água e elaboração dos planos de recursos hídricos. Com estes indicadores, foi possível avaliar: o grau de utilização dos recursos hídricos superficiais, através da relação entre demanda e quantidade hídrica; a capacidade dos corpos d'água de diluir o esgoto doméstico e serem enquadrados em uma das classes de água definidas pela Resolução no.20/86 do CONAMA; capacidade de urbanização, estimada com base no Plano Diretor municipal, permitindo estabelecer a relação entre a disponibilidade e a demanda hídrica futura. Este modelo traz uma abordagem que contribui para gestão do uso dos recursos hídricos em pequenas bacias, mas não deixa explícitos os critérios de seleção dos indicadores como também não contempla a participação dos atores sociais locais. 


\section{Proposta Metodológica para o Desenvolvimento de um Î́ndice de Sustentabilidade Hidroambiental de Áreas Serranas no Semiárido Brasileiro - Estudo de Caso: Maciço de Baturité, Ceará}

A discussão, em questão, tem como objetivo propor uma metodologia para o desenvolvimento de um índice de Sustentabilidade Hidroambiental que permita auxiliar na caracterização da APA de Baturité, no sentido de melhor atender às necessidades das atividades de monitoramento e gerenciamento e de apoiar os Sistemas de Suporte a Decisão do Estado do Ceará. A estrutura aplicada para o desenvolvimento do Índice de Sustentabilidade Hidroambiental foi o modelo PSR (Pressão-Estado-Resposta) onde foram selecionados 28 indicadores levando em consideração a problemática local. Esta pesquisa contribui para gestão dos recursos hídricos, pois a metodologia apresentada deixa bem definidos os critérios de seleção, parâmetros de análises, porém não contempla a participação da população local na seleção dos indicadores.

Analisando os modelos, todos trazem boas contribuições no sentido de mensurar a sustentabilidade para gestão dos recursos hídricos, porém apresentam falhas quanto ao número de indicadores, critérios de seleção e análises como também não fica claro os parâmetros de análises, formas de aplicação e a participação da população local na seleção dos indicadores.

Dentre os modelos, os mais concisos e com melhor facilidade de aplicação são: Indicadores de Sustentabilidade para Gestão de Recursos Hídricos no Âmbito da Bacia Hidrográfica do TietêJacaré-SP; Um Método de Modelagem de um Sistema de Indicadores de Sustentabilidade para Gestão dos Recursos Hídricos-MISGERH: o caso da bacia dos Sinos, o mesmo tem um número razoável de indicadores, estabelece critérios para seleção e avaliação e parâmetros de análises como também contempla a participação da população local, porém esses modelos precisam deixar mais clara a forma de aplicabilidade da ferramenta no intuito de poder ser melhor manuseada pela população local e até mesmo por outras regiões. $\mathrm{Na}$ perspectiva de analisar melhor a sustentabilidade dos recursos hídricos, vários estudos consideram a efetiva participação da comunidade local na elaboração e definição dos sistemas de indicadores destacando a importância da integração da população com a gestão dos recursos hídricos, os quais devem ser considerados um bem comum. Nesse sentido, o anseio da comunidade vai 
estar posto como também o respeito à cidadania, dando oportunidade de participar nas tomadas de decisões e até mesmo na orientação das políticas públicas voltadas à gestão dos recursos hídricos.

\section{Considerações Finais}

Considera-se que os recursos hídricos, além de atender às necessidades humanas, também atendem aos interesses do desenvolvimento os quais eram considerados um bem infinito. Porém, com o mau uso, aliado à crescente demanda, vem preocupando os responsáveis pela gestão dos recursos hídricos, em função da diminuição da disponibilidade de água limpa em todo o planeta. Nesse sentido, apresenta-se um quadro assustador de deficiências: 15 milhões de crianças morrem todo o ano por falta de água potável; $80 \%$ das doenças e 30\% dos óbitos que ocorrem, no mundo, estão relacionados à água contaminada. Nessa perspectiva, a estimativa é que para o ano de 2025 um total de 1,8 bilhão de pessoas de diversos países vão estar vivendo em absoluta falta de água, o que equivale a mais de $30 \%$ da população mundial. Para reverter essa situação, foram criadas diversas ferramentas e diretrizes dentre elas os indicadores de sustentabilidade.

A análise dos diversos modelos de indicadores, utilizados para viabilizar a gestão dos recursos hídricos, permitiu uma visão holística dos vários sistemas utilizados, como também os procedimentos técnicos utilizados para seleção dos indicadores, parâmetros de análises e participação dos atores socais locais. Analisando os modelos de indicadores de sustentabilidade utilizados para a gestão dos recursos hídricos, podese perceber que há uma dificuldade de integrar a população local na seleção dos indicadores. Por isso, é importante à participação dos atores locais, visto que os recursos hídricos são um bem comum que pertence a todos que estão inseridos no contexto.

Foram observadas, durante a pesquisa, algumas inconsistências nos modelos de indicadores pesquisados como:

- Em vários modelos, não são explícitas as forma de aplicação, isso dificulta a reaplicação em outras regiões;

- Quase todos os modelos não apresentam os critérios de seleção dos indicadores como também os parâmetros de análises; 
- Todos os modelos só apresentam uma lista de indicadores, porém não descreve seus objetivos;

- O número de indicadores apresentados pelos modelos em sua maioria são limitados em relação à problemática dos recursos hídricos.

Como os recursos hídricos são essenciais à manutenção da vida e se encontram a beira de um colapso, é necessário criar modelos de indicadores que possam ser mais consistentes, no sentido de corroborar com o diagnóstico das situações atuais e contribuir com a elaboração de estratégias e políticas públicas que visem a minimizar os impactos causados pelo mau uso como também a sua renovação. Portanto, os modelos de indicadores apresentados são limitados e, às vezes, são inconsistentes quanto aos critérios adotados, como também a diversidade de modelos de indicadores é incipiente.

Por isso, a problemática atual dos recursos hídricos exige das instituições de pesquisas uma evolução nos modelos de indicadores de sustentabilidade para gestão dos recursos hídricos, na perspectiva do aprimoramento dos modelos existentes e até mesmo na elaboração de novos modelos mais consistentes, visando a contribuir com a gestão desses recursos. 


\section{Referências}

BARBOSA, D.L. A exploração de um Sistema de reservatórios: UMA análise otimizada dos usos e objetivos múltiplos na Bacia do Rio Capibaribe-Pe. Tese (Doutorado em Recursos Naturais) - Campina Grande - Pb 2008. Disponível em: <http://www.recursosnaturais.ufcg.edu.br/teses/ DayseLBarbosa_2008.pdf >. Acesso em: 01/03/2011.

\section{BARRETO, R.V. Políticas Públicas e o Desenvolvimento Rural}

Sustentável no Estado do Ceará. Dissertação (Mestrado Desenvolvimento Rural e Sustentável). Universidade Federal do Ceará, 2004.

CORRÊA, M. A. et.al. Indicadores de sustentabilidade para gestão de recursos hídricos no âmbito da bacia hidrográfica do Tietê-Jacaré-SP, São Paulo: Universidade Federal de São Carlos, São Paulo, 2006. Disponível em: $<$ http://hygeia.fsp.usp.br/siades/documentos/Publicacoes/artigo_12f.pdf>. Acesso em: 01/03/2011.

EXTERCKOTER, R.K. et al. Uso de indicador no diagnóstico da efetividade no tratamento de água. RBRH - Revista Brasileira de Recursos Hídricos, v.13, n.1, jan./mar. 2008.

FRANCISCO, C. N. Avaliação da sustentabilidade hídrica de municípios abastecidos por pequenas bacias hidrográficas: o caso de Angra dos Reis, RJ. In: CONGRESSO ACADÊMCIO SOBRE MEIO AMBIENTE E DESENVOLVIMENTO DO RIO DE JANEIRO, 1, 2004, Rio de Janeiro. Anais... De 9 e 10 de dezembro de 2004. Fundação Getúlio Vargas. Rio de Janeiro, 2004. Disponível em: <http://www.professores.uff.br/cristiane/Documentos/Artigo\%20cadma\%20final.pdf >. Acesso em: 28/01/2011

GRECCO, D. O planeta está secando. Globo Ciência. Rio de Janeiro, v. 8, n. 85, 1998.

INTERNATIONAL WATER MANAGEMENT INSTITUTE IWMI. Defining the world's water situation in 2025. Disponível em: <http://www.iwmi.cgiar. org/pubs>. Acesso em: 27/02/2011

LAURA, A. A. Um método de modelagem de um sistema de indicadores de sustentabilidade para gestão dos recursos hídricos - MISGERH: 
o caso da Bacia dos Sinos. Tese (Doutorado em Recursos Hídricos e Saneamento Ambiental). Universidade Federal do Rio Grande do Sul. Instituto de Pesquisas Hidráulicas. Programa de Pós-Graduação em Recursos Hídricos e Saneamento Ambiental, 2004. Disponível em: <http:// www.lume.ufrgs.br/handle/10183/6023>. Acesso em: 01/03/2011.

MARTINS, M.F; CANDIDO, G.A. Indicadores de Desenvolvimento Sustentável para Localidades: uma proposta metodológica de construção e análise. In: CANDIDO, G.A. Desenvolvimento Sustentável e Sistemas de Indicadores de Sustentabilidade: formas de aplicação em contextos geográficos diversos e contingências especificas. Campina Grande - PB: Ed. UFCG, 2010. Cap. 1.

. Índice de Desenvolvimento Sustentável - IDS dos Estados brasileiros e dos municípios da Paraíba. Campina Grande: SEBRAE, 2008.

NOSSO FUTURO COMUM. Comissão Mundial sobre o Meio Ambiente e Desenvolvimento. Rio de Janeiro: Fundação Getúlio Vargas, 1991.

NUNES, E.R.M. Metodologia para a Gestão Ambiental de Bacias Hidrográficas com Abrangência para Região Hidrográfica: um Estudo de Caso do Plano Diretor do Programa Pós Guaíba. Tese (Doutorado em Engenharia de Produção) - Programa de Pós-Graduação em Engenharia de Produção, Universidade Federal de Santa Catarina - Florianópolis, 2001.

ORGANIZAÇÃO DAS NAÇÕES UNIDAS - ONU. Falta água potável para 1,1 bilhão no mundo. Paris: ONU, 2006. Disponível em: < http:// www.onu-brasil.org. br/>. Acesso em: 05/02/2011.

RATTNER, H. Tecnologia e Desenvolvimento Sustentável: uma avaliação crítica. Revista de Administração. São Paulo, v. 26, n.01, 1994.

SILVA, A. S. et.al. Índice de Sustentabilidade Ambiental do Uso da Água (ISA_ÁGUA): Municípios da região do entorno do Rio Poxim, SE, Jaguariúna, SP - 2004. Disponível em: <http://www.cnpma.embrapa.br/ download/boletim_22.pdf $>$. Acesso em: 02/03/2011.

VAN BELLEN, Hans Michael. Indicador de Sustentabilidade: uma análise comparativa. Rio de Janeiro: Fundação Getúlio Vargas 2006. 
VASCONCELOS, A. C. F. et al. Análise da Sustentabilidade entre Municípios do Brejo Paraibano : uma aplicação do Índice de Desenvolvimento Sustentável Municipal - IDSM. 2010. In: CANDIDO, G.A. Desenvolvimento Sustentável e Sistemas de Indicadores de Sustentabilidade: formas de aplicação em contextos geográficos diversos e contingências específicas. Campina Grande - PB: Ed. UFCG, 2010. Cap. 7

VIEIRA, P.M.S. et. al. Proposta Metodológica para o Desenvolvimento de um Índice de Sustentabilidade Hidro-Ambiental de Áreas Serranas no Semiárido Brasileiro - Estudo de Caso: Maciço de Baturité, Ceará. RBRH - Revista Brasileira de Recursos Hídrico. Fortaleza, v. 14, n.4, out/dez 2009. Disponível em: <http://www.abrh.org.br/novo/detalha.php?id=556\&t=Proposta+Metodol\%F3gica+para+o+Desenvolvimento+de+um+\%CDndice+de+Sustentabilidade + Hidro + Ambiental + de $+\% \mathrm{C} 1$ reas + Serranas + no + Semi $\% E-$ 1rido+Brasileiro++Estudo+de+Caso\%3A+Maci\%E7o+de+Baturit\%E9\% 2C+Cear\%E1>. Acesso em: 03/01/2011.

WORLD HEALTH ORGANIZATION. Global water supply and sanitation assessment 2000 report. New York, 2001. Disponível em: <http:// www.who. int/ publica-tions/>. Acesso em: 02/03/2011 